\title{
Brainstem auditory evoked potentials in children with microcephaly
}

\author{
Irawan Mangunatmadja, MD; Dwi Putro Widodo, MD; Hardiono D Pusponegoro, MD
}

\begin{abstract}
Background Hearing loss (HL) is commonly found in children with microcephaly. The aim of this study was to reveal hearing loss and auditory brainstem pathways disorders in children with microcephaly and other handicaps.

Methods There were 194 children who were referred for hearing evaluation. Subjects with history of congenital perinatal infection (TORCH) were excluded. Data were collected from the results of Brainstem Auditory Evoked Potentials (BAEP) recordings, including sex, age, clinical manifestations, latency and interlatency between waves I, III, V, and the hearing levels of each ear.

Results Moderate to profound HL were found in fourteen ears (58\%) of patients with microcephaly. Moderate to profound $\mathrm{HL}(28 \%)$ and endocochlear damage (15\%) were found in the ears of patients with microcephaly and delayed speech. Moderate to profound $\mathrm{HL}(39 \%)$ and endocochlear damage $(11 \%)$ were detected in the ears of patients with microcephaly and delayed development. Moderate to profound $\mathrm{HL}(21 \%)$ and endocochlear damage $(16 \%)$ were found in the ears of microcephalic patients with both delayed speech and delayed development. Moderate to profound $\mathrm{HL}(26 \%)$ and endocochlear damage (32\%) were detected in the ears of patients with microcephaly and cerebral palsy.

Conclusion This study revealed the importance of early HL detection in microcephalic patients especially those with other handicaps such as delayed speech, delayed development, and cerebral palsy [Paediatr Indones 2003;43:28-30].
\end{abstract}

Keywords: hearing loss, microcephaly, auditory brainstem pathways.

T The goal of universal hearing screening is to identify children with hearing loss by 3 months of age and to provide appropriate intervention by 6 months of age. Intervention begins before 6 months of age, substantially preceding the speed and language skills of children. ${ }^{1}$ Brainstem Auditory Evoked Potentials
(BAEPs) are used in pediatrics to detect and measure hearing loss in children, especially for those under the age that can be tested behaviorally, and also to evaluate the auditory brainstem pathways in children who may have neurologic problem. ${ }^{2}$

The term microcephaly denotes an occipitofronto circumference that falls two or more standards deviations below the mean head circumference of a certain individual age and gender. Microcephaly necessitates a small brain and implies neurologic impairment. ${ }^{3}$ The aim of this study was to reveal hearing loss and auditory brainstem pathways disorders in children with microcephaly and other handicaps

\section{Methods}

The study was done in the Department of Child Health of Cipto Mangunkusumo Hospital Jakarta. During January 1997 to December 2001, there were 194 children who were referred for hearing evaluation. Subjects with history of congenital perinatal infection $(\mathrm{TORCH})$ were excluded. Data

From the Department of Child Health, Medical School, University of Indonesia, Cipto Mangunkusumo Hospital, Jakarta

Reprint requests to: Irawan Mangunatmaja, MD, Department of child Health, Medical School, University of Indonesia, Cipto Mangunkusumo Hospital, Jakarta, Indonesia. Te. 62-21-390 7740, Fax. 62-21-390 7743 
were collected from the results of BAEP recordings, including sex, age, clinical manifestations, latency and interlatency between waves I, III, V, and the hearing levels of each ear.

The subjects were premedicated, using oral cloralhydrate $50-60 \mathrm{mg} / \mathrm{kg}$, with intramuscular chlorpromazine $1 \mathrm{mg} / \mathrm{kg}$, or the latter alone. Brainstem Auditory Evoked Potentials were recorded with Nihon Koden Neuropack Four Mini. Electrodes were placed on the vertex and ear electrodes were placed on the lateral surfaces of the left and right earlobe (A1, A2). The stimulus click rate was $20 /$ second with a $3 \mathrm{~dB}$ filter and intensities of $80 \mathrm{~dB}$ normal hearing level (nHL). System band-pass for recording was $30-3000 \mathrm{~Hz}$, with an average stimulus of 2040 clicks. Every recording was done at least 2 times for each ear, ${ }^{4}$ and recorded one by one ear for every child. The recordings were analyzed for each ear: the measurement of latency and intervals for waves I, III, and V at $90 \mathrm{dBHL}$ (or $105 \mathrm{dBHL}$ ).

Classification of BAEPs ${ }^{5}$ : (1) normal BAEPs: at $90 \mathrm{dBHL}$, wave I, III, and V peaks latencies and intervals are normal for age within $2 \mathrm{SD}$ range. Electrophysiological hearing threshold is normal with wave $\mathrm{V}$ found at $30 \mathrm{dBHL}$; (2) transmission impairment: at $90 \mathrm{dBHL}$, wave I, III, and V latencies are more than 2 SD above normal of age values; I-III, III-V and I-V intervals are normal for age; electrophysiological hearing threshold is high; wave $\mathrm{V}$ is absent at $30 \mathrm{dBHL}$, but recordable at some higher intensities, (3) endocochlear damage: there is no reproducible wave, not even wave $\mathrm{I}$, at 90 or 105dBHL. Partial damage is characterized by wave I, III, and V latencies and intervals which are normal at 90 or $100 \mathrm{dBHL}$, but electrophysiological hearing threshold above $30 \mathrm{dBHL}$. (4) retrocochlear im- pairment: wave I is present, but wave III and/or V latency is long for age as is the I-V interval. The electrophysiological hearing threshold is variable.

Severity of hearing loss (HL) can be classified as ${ }^{6}:$ (1) none: $0-20 \mathrm{~dB},(2)$ mild: $25-40 \mathrm{~dB},(3)$ moderate: $45-60 \mathrm{~dB},(4)$ severe: $65-80 \mathrm{~dB}$, and (5) profound : $>80 \mathrm{~dB}$.

\section{Results}

In the study period, there were 194 patients (108 males and 86 females) referred to have hearing impairment evaluation. They were between 2 and half months and 7 years old.

Moderate to profound HL were found in fourteen ears of patients with microcephaly. Moderate to profound HL (28\%) and endocochlear damage $(15 \%)$ were found in the ears of patients with microcephaly and delayed speech. Moderate to profound HL (39\%) and endocochlear damage (11\%) were detected in the ears of patients with microcephaly and delayed development. Moderate to profound HL (21\%) and endocochlear damage $(16 \%)$ were found in the ears of microcephalic patients with both delayed speech and delayed development. Moderate to profound HL (26\%) and endocochlear damage (32\%) were detected in the ears of patients with microcephaly and cerebral palsy (Table 1).

One hundred and twenty six patients (65\%) were within the age range of 1 to 4 years. Moderate to profound HL (41\%) and endocochlear damage (19\%) were detected in patients less than 1 year old. Moderate to profound HL (44\%) and endocochlear damage (28\%) were detected in patients aged 1 to 4 years old.(Table 2).

Tabel 1. Distribution of hearing loss based on the patients diagnosis

\begin{tabular}{lllllllll}
\hline Diagnosis & $\begin{array}{l}<\text { 40dB } \\
\text { (normal- } \\
\text { mild) }\end{array}$ & $\mathbf{( \% )}$ & $\begin{array}{l}\mathbf{4 1 - 1 0 5 d B} \\
\text { (moderate- } \\
\text { profound) }\end{array}$ & $\begin{array}{l}\text { (\%) } \\
\text { (endocochlear }\end{array}$ & $\begin{array}{l}\text { 105dB(-) } \\
\text { damage) }\end{array}$ & $\begin{array}{l}\text { Total } \\
\text { ears }\end{array}$ & (\%) \\
\hline $\mathrm{a}$ & 10 & - & 14 & - & 0 & - & 24 & - \\
$\mathrm{a}+\mathrm{b}$ & 47 & $(57)$ & 23 & $(28)$ & 12 & $(15)$ & 82 & $(100)$ \\
$\mathrm{a}+\mathrm{c}$ & 36 & $(50)$ & 28 & $(39)$ & 8 & $(11)$ & 72 & $(100)$ \\
$\mathrm{a}+\mathrm{b}+\mathrm{c}$ & 15 & $(63)$ & 5 & $(21)$ & 4 & $(16)$ & 24 & $(100)$ \\
$\mathrm{a}+\mathrm{d}$ & 79 & $(42)$ & 47 & $(26)$ & 60 & $(32)$ & 186 & $(100)$ \\
Total & 187 & & 117 & & 84 & & 388 & $(100)$ \\
\hline
\end{tabular}

Note : a. microcephaly, b. delayed speech, c. delayed development and d. cerebral palsy 
Paediatrica Indonesiana

Table 2. Distribution of hearing loss based on age

\begin{tabular}{|c|c|c|c|c|c|c|c|c|}
\hline Age (year) & $\begin{array}{l}<40 \mathrm{~dB} \\
\text { (normal } \\
\text { mild) }\end{array}$ & $(\%)$ & $\begin{array}{l}\text { 41-105dB } \\
\text { (moderate- } \\
\text { profound) }\end{array}$ & $(\%)$ & $\begin{array}{l}105 \mathrm{~dB}(-) \\
\text { (endocochlear } \\
\text { damage) }\end{array}$ & (\%) & $\begin{array}{l}\text { Total } \\
\text { ears }\end{array}$ & (\%) \\
\hline$<1$ & 23 & (24) & 39 & (41) & 34 & (35) & 96 & (100) \\
\hline $1-4$ & 142 & (56) & 66 & (26) & 44 & (28) & 252 & (100) \\
\hline$>5$ & 22 & (55) & 12 & (30) & 6 & (15) & 40 & (100) \\
\hline Total & 187 & & 117 & & 84 & & 388 & (100) \\
\hline
\end{tabular}

\section{Discussion}

The risk factors for screening HL in neonates ${ }^{7}$ are one of the following: (1) family history of hereditary childhood HL, (2) congenital perinatal infection (TORCH), (3) malformation of the head or neck, (4) birth weight $<1500$ grams, (5) hyperbilirubinemia, (6) ototoxic medications, (7) bacterial meningitis, (8) 1 minute Apgar score of $0-4$ or 5 minute Apgar score of $0-6,(9)$ mechanical ventilation longer than 5 days, and (10) stigmata of syndromes.

This study found 14 ears patients with microcephaly have moderate to profound HL. The ears of patients with microcephaly and delayed speech showed moderate to profound HL (28\%) and endocochlear damage (15\%). The ears of patients of microcephaly and cerebral palsy showed moderate to profound HL (26\%) and endocochlear damage (32\%). This result support that evaluation of hearing loss are important for patients with speech delay and cerebral palsy. ${ }^{8}$

The ears of patients with microcephaly and delayed development have moderate to profound $\mathrm{HL}$ (39\%) and endocochlear damage (11\%). The ears of patients with microcephaly delayed speech and delayed development have moderate to profound HL (25\%) and endocochlear damage (20\%). Squires et al $(1980)^{9}$ found that $73 \%$ Down syndrome patients had hearing impairment.

About 126 patients (65\%) referred for hearing evaluation with age between $1-4$ years old. Their ears have moderate to profound HL (26\%) and endocochlear damage (28\%). Patients with age below 1 year old had ears with endocochlear damage $(35 \%)$. This finding support the recommendation to screen hearing loss in babies below 6 months of age. ${ }^{1}$
In conclusion, this study revealed the importance of early HL detection in microcephalic patients especially those with other handicaps such as delayed speech, delayed development and cerebral palsy.

\section{References}

1. Erenberg S. Automated auditory brainstem response testing for universal newborn hearing screening. Otolaryng Clin North Am 1999;32:993-7

2 Picton TW, Taylor MG, Durieux-Smith A. Brainstem auditory evoked potentials in infants and children. In: Aminoff MJ, editor. Electrodiagnosis in clinical neurology, $4^{\text {th }} \mathrm{ed}$. New York: Churchill Livingstone; 1999. p. 485-511

3. DeMyer W. Microcephaly, micrencephaly, megalocephaly and megalencephaly. In: Swiman KE, Ashwal S, editors. Pediatric neurology: principles \& practice. $3^{\text {rd }}$ ed St Louis: Mosby; 1999. p. 1438-69

4. American Electroencephalographic Society. Guideline for clinical evoked potential studies. J Clin Neurophysiol 1984; 1:3-54

5. Duclaux R, Sevin F, Ferber C, Drai MF, Dubreui C. Brainstem auditory evoked potentials following meningitis in children. Brain Dev 1993;340-5

6. Rapin I. Hearing impairment. In: Swiman KE, Ashwal S, editors. Pediatric neurology: principles \& practice. $3^{\text {rd }}$ ed. St Louis: Mosby; 1999. p. 77-95

7. Joint Committee on Infant Hearing: 1994 position statement. ASHA 1994; 36:38 - 42

8. Leung AKC, Kao CP. Evaluation and management of the child with speech delayed. Am Fam Phys 1999; 59:282-6

9. Squires N, Aine C, Buchwald J, Norman R, Galbraith G. Auditory brainstem responses abnormality in severely and profoundly retarded adult. Electrocephalogr Clin Neurophysiol 1980; 50:172-85 